\title{
The Effect of Coconut Water and Boiling on Antioxidant Activity and Total Phenolic Contents in Schizophyllum commune Fr.
}

\author{
Chanate Wanna ${ }^{1 *}$, Montarop Sudhadham ${ }^{2}$
}

\section{Chanate Wanna ${ }^{1 *}$ and Montarop Sudhadham ${ }^{2}$}

'Division of Biology, Faculty of Science and Technology, Suan Sunandha Rajabhat University, Bangkok 10300, THAILAND.

${ }^{2}$ Division of Biology, Faculty of Science and Technology, Suan Sunandha Rajabhat University, Bangkok 10300, THAILAND.

\section{Correspondence}

\section{Chanate Wanna}

Division of Biology, Faculty of Science and Technology, Suan Sunandha Rajabhat University, Bangkok 10300 THAILAND.

Phone No: +6621601143; $+66896678880$

E-mail: chanate.wa@ssru.ac.th

History

- Submission Date: 24-01-2018;

- Review completed: 06-03-2018;

- Accepted Date: 03-05-2018

DOI : 10.5530/pj.2018.5.156

Article Available online

http://www.phcogj.com/v10/i5

\section{Copyright}

(C) 2018 Phcog.Net. This is an openaccess article distributed under the terms of the Creative Commons Attribution 4.0 International license.

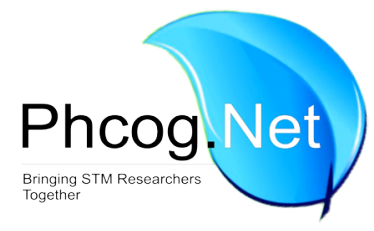

\begin{abstract}
Context: Schizophyllum commune Fr., a split gill mushroom has been acknowledged for its medicinal properties. Aims: The present study was to evaluate the effect of coconut water and boiling on antioxidant activity and total phenolic contents in Schizophyllum commune Fr. Settings and Design: The experiment was completely randomized design (CRD) using tender and mature coconut water compared to synthetic hormone at concentration of $50 \%$ and $100 \%$ in volume of 5 and $10 \mathrm{ml}$. The first group is fresh mushrooms and the second group is boiled mushroom then was dried in hot air oven at $45^{\circ} \mathrm{C}$ for $48 \mathrm{hr}$. Materials and Methods: The S. commune was extracted with ethanol and then was evaluated the scavenging activity by DPPH and FRAP assay and Folin-Ciocalteau method was used to determine total phenolic contents. Statistical analysis used: The data were recorded as means \pm standard deviations and analyzed by using SPSS version 21. The mean values of data were subjected to a oneway analysis of variance (ANOVA) and the significance of the difference between means was determined by the Tukey's multiple comparison tests at $95 \%$ least significance difference $(p<0.05)$. Pearson correlation coefficient was used to determine the relationship between the antioxidant activity and total phenolic contents in sample extracts. Results: In fresh mushroom group showed higher antioxidant activity and total phenolic contents than boiled mushroom group. When compared to a loss of antioxidant activity and total phenolic contents after boiling only the experiments with coconut water found that tender coconut water $50 \%$ of $5 \mathrm{ml}$ has the lowest of loss in TEAC and total phenolic contents as $9.28 \%$ and $9.85 \%$ respectively. Mature coconut water $100 \%$ of $10 \mathrm{ml}$ has the lowest of loss in FRAP as $2.77 \%$ and followed by tender coconut water $50 \%$ of $5 \mathrm{ml}$ as $4.82 \%$ which were lower than control treatment but similar with synthetic hormone of $5 \mathrm{ml}$. The relationship between antioxidant activity and total phenolic contents of mushrooms was low in both groups. Conclusion: It concluded that tender coconut water $50 \%$ of $5 \mathrm{ml}$ could maintain the antioxidant properties and total phenolic compounds in S. commune.

Key-words: Antioxidant, Free radicals, Total phenolic contents, Coconut water, Schizophyllum commune Fr.

Key Messages: The tender coconut water $50 \%$ of $5 \mathrm{ml}$ was suitable for holding the antioxidant properties and total phenolic contents and also boiling affect to loss of antioxidant compounds in S. commune. The findings from this study provide information for alternative selection of coconut water as natural hormone.
\end{abstract}

\section{INTRODUCTION}

Currently, most people realize the health care and greater emphasis on the consumption of dietary antioxidants. Naturally occurring antioxidants which can be found in diets have important ability to protect cells from damage by free radicals through inhibiting oxidation that lead to degenerative diseases. ${ }^{1}$ Many oxidative stresses which are excess free radicals cause cellular degeneration due to damaging all components of body including DNA, proteins, lipids and sugars ${ }^{2}$ and related various diseases such as cancer, high blood pressure, coronary heart disease and diabetes., Almost all organisms possess natural antioxidants such as glutathione created within cells defines and repair systems that have evolved to protect them against the oxidative damage. However, these systems are insufficient to prevent the damage entirely. Thus, exogenous addition of dietary antioxidants such as phenolic compounds that is beneficial as possible protective agents to help the endogenous system of human body by scavenging the free radicals that reduce the oxidative damage and diseases. ${ }^{5}$

Mushrooms are known to be antioxidant natural products that have great potential as biologically functional food and source of physiologically benefits. ${ }^{6}$ Many studies have found that mushrooms are having various therapeutic properties such as antioxidants, antimicrobial, anticancer, anti-inflammatory, antidiabetic, cardioprotective and immune stimulatory effects. ${ }^{7,8}$ They usually contain a variety of different bioactive compounds like polysaccharides,
Cite this article: Wanna $\mathrm{C}$ and Sudhadham M. The Effect of Coconut Water and Boiling on Antioxidant Activity and Total Phenolic Contents in Schizophyllum commune Fr. Pharmacog J. 2018;10(5):925-31. 
phenolic acids, flavonoids, anthocyanins, carotenoids, essential amino acids, fiber, important fatty acids, minerals and vitamins as defences against degenerative diseases. ${ }^{9,10}$

Schizophyllum commune Fr., commonly known as split gill, is one of the edible mushrooms and has been consumed widely as a nutritional diet in South-east Asia and is being cultivated in Malaysia and Southern Thailand. ${ }^{11}$ It belongs to basidiomycetes which is saprophyte on dead wood. The fruiting body of $S$. commune, about $1-5 \mathrm{~cm}$ wide, fan-shaped ${ }^{12}$ consists of water-soluble homopolysaccharide called schizophyllan. The antioxidant compounds in this mushroom can scavenge free radicals to protect the oxidative damage in living organisms. ${ }^{13}$ The coconut water is rich in many nutrients, including sugars, protein, vitamins and minerals. It also contains chemicals that help regulate growth and stimulate cell division of mushroom mycelium. The mushrooms must be such nutrients as a source of energy for growth and flowering. Therefore, the coconut water may increase the active ingredients for antioxidant in mushroom. Hence, the present study is to determine the effect of coconut water and boiling on the antioxidant properties and total phenolic contents in S. commune extracts based on in vitro antioxidant assay.

\section{MATERIALS AND METHODS}

\section{Chemicals}

2,2-diphenyl-1-picrylhydrazyl (DPPH) (Sigma-Aldrich), 6-hydroxy-2,5,7,8tetramethyl chroman-2-carboxylic acid (trolox) (Sigma Aldrich), 2,4,6-tris (2- pyridyl)-s -triazine (TPTZ) (Sigma-Aldrich), Folin-Ciocalteu's phenol reagent (LoBA Chemie), gallic acid monohydrate (Sigma-Aldrich), hydrochloric acid (Gammaco), acetic acid (Gammaco), sodium acetate (Ajax Finechem), iron (III) chloride hexahydrate (Applichem), ferrous (II) sulphate (Gammaco), sodium carbonate anhydrous $\left(\mathrm{Na}_{2} \mathrm{CO}_{3}\right)$ (Gammaco), ethanol (Merck).

\section{Cultivation of S. commune fruiting bodies}

S. commune was taken from Aranyik Mushroom Center, Nakhon Pathom province which produce good quality mushroom. This research was divided into triplication of 11 treatments using 50 mushrooms in each treatment and inject with synthetic hormone, tender coconut water and mature coconut water at various concentration and volume using water as control.

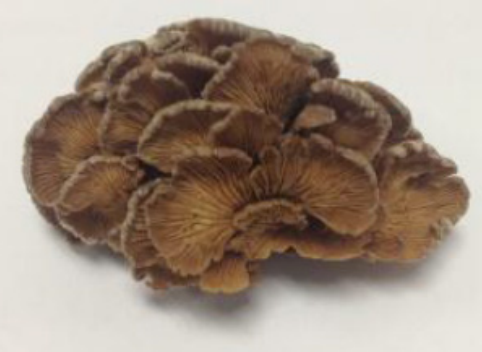

\section{$\overline{1 \mathrm{~cm}}$}

Figure 1: The matured fruit body of split gill mushroom (Schizophyllum commune Fr.)

\section{Preparation of S. commune extracts}

$S$. commune fruit bodies were washed and then divided the mushrooms into two groups: group 1 was the group of fresh mushrooms and group 2 was the mushrooms though boiling at $90^{\circ} \mathrm{C}$ for $5 \mathrm{~min}$. Both groups were air dried followed by drying in an oven at $45^{\circ} \mathrm{C}$ for $48 \mathrm{~h}$. The fruiting bodies were cut into small pieces and weighing $30 \mathrm{~g}$ were extracted with $150 \mathrm{ml}$ of ethanol. The mixture was placed in a conical flask (wrapped with an aluminium foil) and agitated at $200 \mathrm{rpm}$ with shaker for $72 \mathrm{~h}$. The extract was separated from the residue by filtration through Whatman No.1 filter paper. The remaining residue was re-extracted twice, and then the two extracts were combined. The residual solvent of ethanol extracts was removed under reduced pressure at $70^{\circ} \mathrm{C}$ using a rotary evaporator until complete dryness to obtain the crude extract. The obtained concentrated extracts were diluted in ethanol for DPPH assay, FRAP assay and Folin-Ciocalteu assay.

\section{Determination of S. commune extracts yield}

The yields of evaporated dried extracts were obtained by gravimetric method. The percentage yield extracts were calculated based on dry weight as:

$$
\text { Yield }(\%)=\left(\mathrm{W}_{1} / \mathrm{W}_{2}\right) \times 100
$$

Where, $\quad \mathrm{W}_{1}$ is the weight of extract after ethanol evaporation $\mathrm{W}_{2}$ is the weight of extract mushroom

\section{DPPH free radical scavenging activity assay}

This assay was used to evaluate antioxidant activity of $S$. commune extracts from purple to yellow through 2, 2-diphenyl-1-picrylhydrazyl (DPPH) scavenging system. ${ }^{14}$ The stock of $0.3 \mathrm{mM}$ DPPH solution was prepared by dissolving $5.9 \mathrm{mg}$ DPPH powder in $50 \mathrm{ml}$ of ethanol, sealed in aluminium foil and kept in a fridge. Accurately $100 \mu \mathrm{l}$ of $S$. commune extract was mixed with $900 \mu \mathrm{l}$ of $0.3 \mathrm{mM}$ DPPH solution. The mixture was shaken vigorously and left to stand for $30 \mathrm{~min}$ in the dark at room temperature. The reaction mixture was measured against a blank (ethanol) at $515 \mathrm{~nm}$ with UV-VIS spectrophotometer (Thermo GENESYS 20). Each free radical scavenging activity assay was carried out in triplicate from the same extract to determine their reproducibility and the results were expressed as mean values \pm standard deviations for the three readings were statistically determined. The percentage of free radical DPPH scavenging activity of the extract in two groups was calculated as:

$$
\text { DPPH scavenging activity }(\%)=\left[\left(\mathrm{A}_{\text {control }}-\mathrm{A}_{\text {extract }}\right) / \mathrm{A}_{\text {control }}\right] \times 100
$$

Where, $\mathrm{A}_{\text {control }}$ is the absorbance of control solution containing only $\mathrm{DPPH}$

$\mathrm{A}_{\text {extract }}$ is the absorbance of mushroom extract in DPPH solution

The result was reported as $\mathrm{mM}$ of trolox equivalent antioxidant capacity (TEAC) using the graph by plotting of standard curve using trolox as a standard control between inhibition percentage against trolox concentration at $0.02,0.04,0.08,0.16,0.24,0.36,0.40$ and $0.48 \mathrm{mM}$.

\section{Ferric reducing antioxidant power (FRAP) assay}

FRAP assay uses antioxidants as reductants in redox-linked colorimetric method..$^{15}$ FRAP reagent was prepared fresh using $0.2 \mathrm{M}$ acetate buffer, pH $3.6(0.2 \mathrm{M}$ acetic acid $46.3 \mathrm{ml}$ and $0.2 \mathrm{M}$ sodium acetate $3.7 \mathrm{ml}), 1$ $\mathrm{mM}$ TPTZ (2,4,6-tris (2- pyridyl)-s-triazine) in $40 \mathrm{mM} \mathrm{HCl}$ and $20 \mathrm{mM}$ $\mathrm{FeCl}_{3} \cdot 6 \mathrm{H}_{2} \mathrm{O}$ in the ratio of 10:1:1 to mix the working reagent and then incubate $37^{\circ} \mathrm{C}$ for $20 \mathrm{~min}$. Accurately $100 \mu \mathrm{l}$ of $S$. commune extract was added to $1.5 \mathrm{ml}$ of FRAP reagent and left to stand for $30 \mathrm{~min}$ in the dark at room temperature. The reduction of ferric $\left(\mathrm{Fe}^{3+}\right)$ (colourless) to fer- 
rous $\left(\mathrm{Fe}^{2+}\right.$ ) (blue) can be monitored by measuring absorbance at $595 \mathrm{~nm}$ wavelength using a UV-VIS spectrophotometer after $30 \mathrm{~min}$. Calibration curve of ferrous (III) sulfate $\left(\mathrm{FeSO}_{4}\right)$ at $0.2,0.4,0.6,0.8,1.0$ and $1.2 \mathrm{mM}$ $\mathrm{Fe}^{2+}$ equivalents was set up to estimate the activity capacity of samples. Result was expressed as $\mathrm{mM}$ of $\mathrm{Fe}^{2+}$ equivalents per gram of extract ( $\mathrm{mM}$ $\mathrm{Fe}^{2+} / \mathrm{g}$ extract).

\section{Determination of total phenolic contents}

The total phenolic contents of $S$. commune extracts were determined by Folin-Ciocalteu colorimetric method. ${ }^{16}$ Each $100 \mu \mathrm{l}$ of $S$. commune extract was mixed thoroughly with $900 \mu \mathrm{l}$ of $10 \%$ Folin-Ciocalteau reagent and left to stand for $8 \mathrm{~min}$ at room temperature. Then $400 \mu \mathrm{l}$ of $7.5 \%(\mathrm{w} / \mathrm{v})$ sodium carbonate was added to the mixture and was agitated for further $60 \mathrm{~min}$ in the dark. The absorbance of mushroom extract and prepared blank were measured at $765 \mathrm{~nm}$ for blue colored complex using UV-VIS spectrophotometer. A calibration curve was constructed with different concentrations of gallic acid ranging from 1 to $80 \mathrm{mg} / \mathrm{ml}$. The results were expressed as $\mathrm{mg}$ of gallic acid equivalents (GAE) per gram of extract (mg GAE/g extract).

\section{Statistical analysis}

All analyses were performed in triplicate $(n=3)$. The data were recorded as means \pm standard deviations and analyzed by using Statistical Package for Social Sciences (SPSS version 21). The mean values of data were subjected to a one-way analysis of variance (ANOVA) and the significance of the difference between means was determined by the Tukey's multiple comparison tests at $95 \%$ least significance difference $(\mathrm{p}<0.05)$. Pearson correlation coefficient was used to determine the relationship between the antioxidant activity and total phenolic contents in sample extracts. Differences between means at $\mathrm{p}<0.05$ level were considered to be significant.

\section{RESULTS}

\section{Total yield of S. commune extracts}

The percentage of S. commune yield is shown in Table 1. Total yield of S. commune ethanolic extracts is ranging from $1.23 \%$ to $8.26 \%$. The highest yield is contributed to $50 \%$ mature coconut water of $5 \mathrm{ml}$ in boiled mushroom to $8.26 \%$ and has the lowest yield of $1.23 \%$ in fresh mushroom, it is believed that it contains more water-soluble substances.

Table 1: Total yield of crude extracts from S. commune in each group.

\begin{tabular}{cccc}
\hline & Volume & & \multicolumn{2}{c}{ Total yield of extract (\%) } \\
\cline { 3 - 4 }$(\mathrm{ml})$ & $\begin{array}{c}\text { Fresh } \\
\text { mushroom }\end{array}$ & $\begin{array}{c}\text { Boiled } \\
\text { mushroom }\end{array}$ \\
\hline 1. Control (water) & - & 2.86 & 3.16 \\
2. Synthetic hormone & 5 & 2.66 & 1.73 \\
3. Tender coconut water 50\% & 10 & 2.33 & 6.23 \\
4. Tender coconut water 100\% & 5 & 3.20 & 3.06 \\
5. Mature coconut water 50\% & 10 & 3.16 & 3.66 \\
& 5 & 1.90 & 4.23 \\
6. Mature coconut water 100\% & 10 & 2.23 & 3.13 \\
& 5 & 1.23 & 8.26 \\
& 10 & 2.10 & 5.63 \\
& 5 & 2.86 & 2.96 \\
\end{tabular}

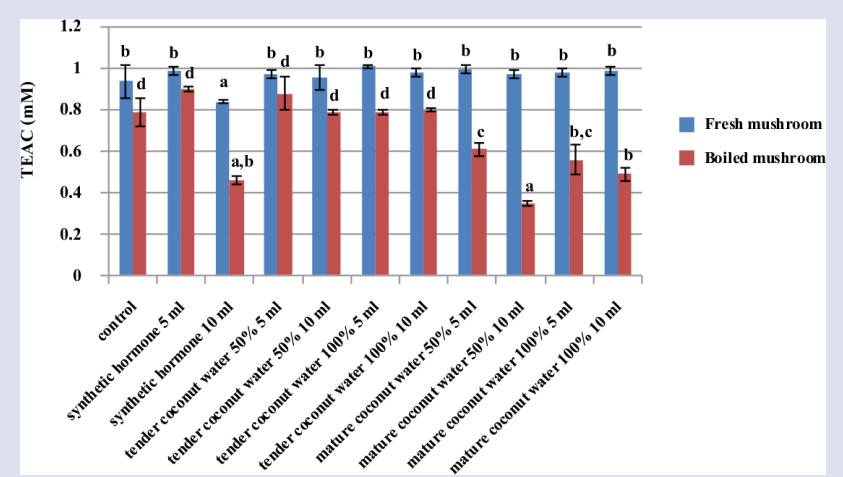

Figure 2: Antioxidant capacity of S. commune in each group with DPPH assay.

\section{Analysis of antioxidant activity of S. commune extracts with DPPH assay}

To determine the antioxidant activity of $S$. commune extracts in DPPH assay. It measures the ability of the extracts to inhibit free radical DPPH which changes from purple to yellow as compared to the standard solution of trolox. The results found that $S$. commune extracts of fresh mushroom have higher than boiled mushroom in every treatment (F-test $=999.482$; $\mathrm{p}<0.05$ ). Considering only the fresh mushroom showed that the TEAC values of all treatments are the same except for the treatment of synthetic hormone of $10 \mathrm{ml}$ is different from other treatments (F-test $=5.311$; $\mathrm{p}<0.05)$. Mushroom extracts with the $100 \%$ tender coconut water at $5 \mathrm{ml}$ is the highest TEAC as $1.01 \pm 0.01 \mathrm{mM}$, followed by $50 \%$ mature coconut water in $5 \mathrm{ml}$ and $100 \%$ mature coconut water in $10 \mathrm{ml}$ which have TEAC value as $1.00 \pm 0.02$ and $0.99 \pm 0.02 \mathrm{mM}$, respectively. Tender coconut water of boiled mushroom has the DPPH radical scavenging ability like the $5 \mathrm{ml}$ of synthetic hormone treatment and higher than mature coconut and $10 \mathrm{ml}$ of synthetic hormone (F-test $=63.778$; $\mathrm{p}<0.05)$. In addition, considering the loss of the TEAC each treatment showed that $50 \%$ of mature coconut water in $10 \mathrm{ml}$ which is decreased the most is $63.92 \%$ and $5 \mathrm{ml}$ of synthetic hormone is reduced the least equal to $9.09 \%$. By increasing the volume of hormones and coconut water tend to lose the TEAC up almost all treatments except the 100\% tender coconut water shown in Table 2 and Figure 2.

\section{Analysis of antioxidant activity of S. commune extracts with FRAP assay}

The antioxidant activity analysis of the $S$. commune extracts with FRAP assay which measured the ability of reducing ferric ions $\left(\mathrm{Fe}^{3+}\right)$ as the ferrous ions $\left(\mathrm{Fe}^{2+}\right)$ of the extract. The reaction which changed from colorless to blue reported as reducing power or the FRAP value. Both experimental groups and treatments affect the FRAP value, the FRAP value of fresh mushrooms is higher than the boiled mushroom and all treatments are similar in each group (F-test $=6582.906 ; \mathrm{p}<0.05$ ). The $100 \%$ of mature coconut water in $10 \mathrm{ml}$ has the most FRAP value as $4.05 \pm 0.00 \mathrm{mM}$, followed by $100 \%$ of tender coconut water in $5 \mathrm{ml}$ equal to $4.04 \pm 0.02 \mathrm{mM}$ unlike other treatments was statistically significant in the fresh mushroom group (F-test $=15.791 ; \mathrm{p}<0.05)$. In boiled mushroom group, $100 \%$ of tender coconut water volume in $10 \mathrm{ml}$ has the most FRAP value as $3.86 \pm 0.02 \mathrm{mM}$, followed by $50 \%$ of tender coconut water and synthetic hormone in $5 \mathrm{ml}$ are equal to $3.75 \pm 0.02 \mathrm{mM}$ which is significantly higher than the control, $10 \mathrm{ml}$ of synthetic hormone and mature coconut water $(\mathrm{F}$-test $=342.087 ; \mathrm{p}<0.05)$. Corresponding to the percentage loss of the FRAP value showed that tender coconut water and 
Wanna and Sudhadham: Coconut water and boiling act on S. commune Fr. antioxidant

Table 2: The scavenging activity of S. commune extracts as measured with DPPH radical scavenging assay.

\begin{tabular}{|c|c|c|c|c|}
\hline \multirow{2}{*}{ Treatment } & \multirow{2}{*}{ Volume (ml) } & \multicolumn{3}{|c|}{ TEAC value (mM TEAC) } \\
\hline & & Fresh mushroom & Boiled mushroom & TEAC loss (\%) \\
\hline 1. Control (water) & - & $0.94 \pm 0.08^{b}$ & $0.79 \pm 0.07^{d}$ & 15.96 \\
\hline \multirow{2}{*}{$\begin{array}{l}\text { 2. Synthetic } \\
\text { hormone }\end{array}$} & 5 & $0.99 \pm 0.02^{b}$ & $0.90 \pm 0.01^{\mathrm{d}}$ & 9.09 \\
\hline & 10 & $0.84 \pm 0.01^{\mathrm{a}}$ & $0.46 \pm 0.02^{\mathrm{a}, \mathrm{b}}$ & 45.24 \\
\hline \multirow{2}{*}{$\begin{array}{c}\text { 3. Tender coconut } \\
\text { water } 50 \%\end{array}$} & 5 & $0.97 \pm 0.02^{\mathrm{b}}$ & $0.88 \pm 0.08^{d}$ & 9.28 \\
\hline & 10 & $0.96 \pm 0.06^{\mathrm{b}}$ & $0.79 \pm 0.01^{\mathrm{d}}$ & 17.71 \\
\hline \multirow{2}{*}{$\begin{array}{l}\text { 4. Tender coconut } \\
\text { water } 100 \%\end{array}$} & 5 & $1.01 \pm 0.01^{\mathrm{b}}$ & $0.79 \pm 0.01^{\mathrm{d}}$ & 21.78 \\
\hline & 10 & $0.98 \pm 0.02^{\mathrm{b}}$ & $0.80 \pm 0.01^{\mathrm{d}}$ & 18.37 \\
\hline \multirow{2}{*}{$\begin{array}{c}\text { 5. Mature coconut } \\
\text { water } 50 \%\end{array}$} & 5 & $1.00 \pm 0.02^{\mathrm{b}}$ & $0.61 \pm 0.03^{c}$ & 39.00 \\
\hline & 10 & $0.97 \pm 0.02^{b}$ & $0.35 \pm 0.01^{\mathrm{a}}$ & 63.92 \\
\hline \multirow{2}{*}{$\begin{array}{l}\text { 6. Mature coconut } \\
\text { water } 100 \%\end{array}$} & 5 & $0.98 \pm 0.02^{\mathrm{b}}$ & $0.56 \pm 0.07^{b, c}$ & 42.86 \\
\hline & 10 & $0.99 \pm 0.02^{b}$ & $0.49 \pm 0.03^{b}$ & 50.51 \\
\hline
\end{tabular}

Values are expressed as mean \pm SD $(n=3)$ of triplicate measurements.

Different letters in the column indicate significant differences at $\mathrm{p}<0.05$.

Table 3: The reducing power of S. commune extracts as measured with FRAP assay.

\begin{tabular}{|c|c|c|c|c|}
\hline \multirow{2}{*}{ Treatment } & \multirow{2}{*}{ Volume (ml) } & \multicolumn{3}{|c|}{ FRAP value (mM Fe ${ }^{2+} / \mathrm{g}$ extract) } \\
\hline & & Fresh mushroom & Boiled mushroom & FRAP loss (\%) \\
\hline 1. Control (water) & - & $3.95 \pm 0.01^{\mathrm{a}, \mathrm{b}}$ & $2.61 \pm 0.04^{b, c}$ & 33.92 \\
\hline \multirow{2}{*}{ 2. Synthetic hormone } & 5 & $3.98 \pm 0.03^{\mathrm{b}, c, \mathrm{~d}}$ & $3.75 \pm 0.04^{\mathrm{f}, \mathrm{g}}$ & 5.78 \\
\hline & 10 & $3.92 \pm 0.01^{\mathrm{a}}$ & $2.55 \pm 0.05^{\mathrm{b}}$ & 34.95 \\
\hline \multirow{2}{*}{ 3. Tender coconut water $50 \%$} & 5 & $3.94 \pm 0.01^{\mathrm{a}, \mathrm{b}}$ & $3.75 \pm 0.02^{f, g}$ & 4.82 \\
\hline & 10 & $3.96 \pm 0.04^{\mathrm{a}, \mathrm{b}, \mathrm{c}}$ & $3.48 \pm 0.04^{\mathrm{e}}$ & 12.12 \\
\hline \multirow{2}{*}{ 4. Tender coconut water $100 \%$} & 5 & $4.04 \pm 0.02^{\mathrm{e}}$ & $3.71 \pm 0.04^{\mathrm{f}}$ & 8.17 \\
\hline & 10 & $3.97 \pm 0.00^{\mathrm{a}, \mathrm{b}, \mathrm{c}, \mathrm{d}}$ & $3.86 \pm 0.02^{\mathrm{g}}$ & 2.77 \\
\hline \multirow{2}{*}{ 5. Mature coconut water $50 \%$} & 5 & $4.01 \pm 0.01^{c, \mathrm{~d}, \mathrm{e}}$ & $3.29 \pm 0.11^{\mathrm{d}}$ & 17.96 \\
\hline & 10 & $4.00 \pm 0.02^{c, \mathrm{~d}, \mathrm{e}}$ & $2.37 \pm 0.07^{\mathrm{a}}$ & 40.75 \\
\hline \multirow{2}{*}{ 6. Mature coconut water $100 \%$} & 5 & $4.02 \pm 0.02^{\mathrm{d}, \mathrm{e}}$ & $3.21 \pm 0.05^{d}$ & 20.15 \\
\hline & 10 & $4.05 \pm 0.00^{\mathrm{e}}$ & $2.71 \pm 0.03^{c}$ & 33.09 \\
\hline
\end{tabular}

Values are expressed as mean $\pm \mathrm{SD}(\mathrm{n}=3)$ of triplicate measurements.

Different letters in the column indicate significant differences at $\mathrm{p}<0.05$.

synthetic hormone in $5 \mathrm{ml}$ are lower than other treatments. In descending order of percentage loss of the FRAP value as 100\% tender coconut water in $10 \mathrm{ml}, 50 \%$ tender coconut water in $5 \mathrm{ml}$ and $5 \mathrm{ml}$ synthetic hormones are $2.77 \%, 4.82 \%$ and $5.78 \%$, respectively shown in Table 3 and Figure 3.

\section{Determination the total phenolic contents of $S$. commune extracts}

Quantitative analysis of total phenolic compounds in S. commune extracts by Folin-Ciocalteu assay found that the fresh mushroom extract in all treatments were the total phenolic contents higher than the boiled mushroom extracts to be statistically significant (F-test $=3991.443$; $\mathrm{p}<0.05$ ). The $100 \%$ of tender and mature coconut water in $5 \mathrm{ml}$ had the total phenolic contents similar levels of $247.45 \pm 3.84$ and $247.49 \pm 1.42$ mg GAE/g extract, respectively and were statistically significant higher than the control and synthetic hormone. Considering the reduction of the amount of total phenolic contents in each treatment after the boiled process showed that the $100 \%$ of mature coconut water in $10 \mathrm{ml}$ was the most of total phenolic contents loss equal to $49.96 \%$ and the least of loss as $50 \%$ of tender coconut water in $5 \mathrm{ml}$ equal to $9.85 \%$. Also be noted that the use of coconut water and synthetic hormone in volume of $5 \mathrm{ml}$ is likely to lose the amount of total phenolic contents less than in volume of $10 \mathrm{ml}$ shown in Table 4 and Figure 4.

\section{Correlation between antioxidant activity and total phenolic contents of S. commune extracts}

The correlation between the antioxidant assays and the total phenolic contents of $S$. commune extracts was performed using Pearson correlation of SPSS program. Almost antioxidant assays results exhibited positive correlation except DPPH and Folin-Ciocalteu assay in boiled mushroom (Table 5). DPPH and FRAP assays in boiled mushroom showed the highest correlation among the $S$. commune extracts $\left(\mathrm{R}^{2}=0.797\right)$. The relation 
Table 4: The total phenolic contents of $S$. commune extracts as measured with Folin-Ciocalteu assay.

\begin{tabular}{ccccc}
\multirow{2}{*}{ Treatment } & & \multicolumn{3}{c}{$\begin{array}{c}\text { Total phenolic contents } \\
\text { (mg GAE/g extract) }\end{array}$} \\
\cline { 3 - 5 } Volume $(\mathrm{ml})$ & Boiled mushroom & TPC loss (\%) \\
\cline { 3 - 5 } 1. Control (water) & - & $115.08 \pm 5.23^{\mathrm{a}}$ & $92.93 \pm 2.23^{\mathrm{a}}$ & 19.25 \\
2. Synthetic hormone & 5 & $129.30 \pm 4.87^{\mathrm{b}}$ & $115.71 \pm 3.79^{\mathrm{b}}$ & 10.51 \\
& 10 & $160.53 \pm 5.62^{\mathrm{d}}$ & $113.82 \pm 5.84^{\mathrm{b}}$ & 29.10 \\
3. Tender coconut water 50\% & 5 & $128.56 \pm 2.71^{\mathrm{b}}$ & $115.90 \pm 2.45^{\mathrm{b}}$ & 9.85 \\
4. Tender coconut water 100\% & 10 & $140.49 \pm 2.39^{\mathrm{c}}$ & $101.90 \pm 3.26^{\mathrm{a}}$ & 27.47 \\
5. Mature coconut water 50\% & 5 & $247.45 \pm 3.84^{\mathrm{h}}$ & $147.34 \pm 4.56^{\mathrm{d}}$ & 40.46 \\
6. Mature coconut water 100\% & 10 & $205.34 \pm 1.95^{\mathrm{f}}$ & $164.30 \pm 1.14^{\mathrm{e}}$ & 19.99 \\
& 5 & $234.45 \pm 1.56^{\mathrm{g}}$ & $163.90 \pm 3.26^{\mathrm{e}}$ & 30.09 \\
\hline
\end{tabular}

Values are expressed as mean $\pm S D(n=3)$ of triplicate measurements.

Different letters in the column indicate significant differences at $\mathrm{p}<0.05$.

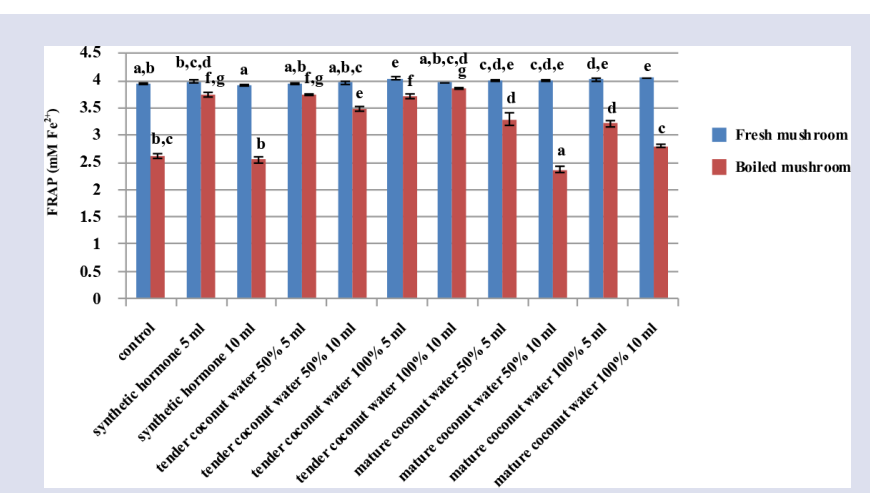

Figure 3: Reducing power of S. commune in each group with FRAP assay.

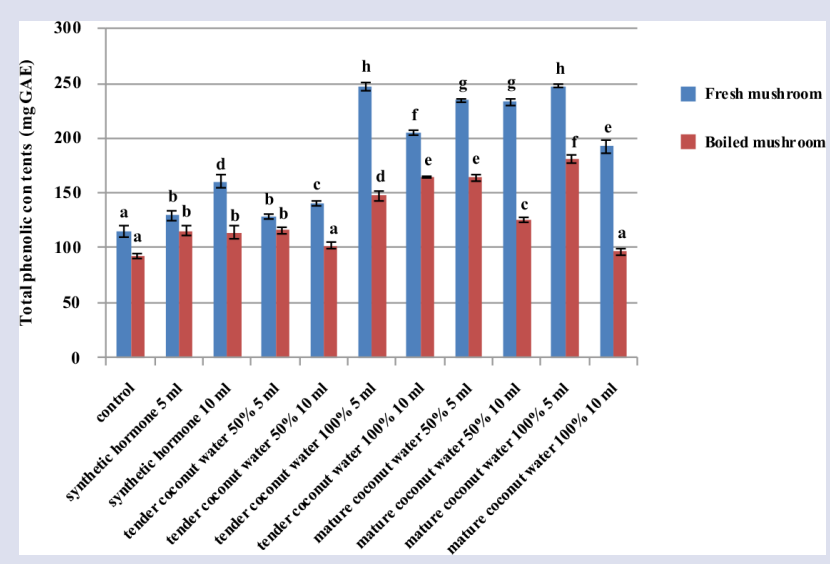

Figure 4: Determination of total phenolic contents of S. commune in each group with Folin-Ciocalteu assay.
Table 5: Correlation coefficients among the antioxidant activities and total phenolic contents (TPC) of S. commune in each group.

\begin{tabular}{rcccccc}
\hline \multirow{2}{*}{ Assay } & \multicolumn{3}{c}{ Fresh mushroom } & \multicolumn{3}{c}{ Boiled mushroom } \\
\cline { 2 - 7 } & DPPH & FRAP & TPC & DPPH & FRAP & TPC \\
\hline DPPH & - & - & - & - & - & - \\
FRAP & 0.634 & - & - & 0.797 & - & - \\
TPC & 0.325 & 0.680 & - & -0.064 & 0.376 & - \\
\hline
\end{tabular}

between the amount of phenolic contents and antioxidant activity when tested by FRAP assay was positive equal to 0.376 and tested with DPPH was negative equal to -0.064 in the boiled mushroom whereas antioxidant activity relative to the amount of total phenolic contents in fresh mushrooms. It was showed that the relationship between the amount of phenolic contents and antioxidant activity when tested by FRAP assay had a relatively high correlation coefficient equal to 0.680 and tested by DPPH assay had relatively low value of 0.325 .

\section{DISCUSSION}

According to the results, it found that the S. commune extract with tender coconut water has a high antioxidant activity and percentage loss of FRAP and TEAC likely lower compared to other treatments. Probably due to the tender coconut water has essential amino acid to necessary for the growth of mushrooms which are relatively high. As a result, the antioxidant activity in mushrooms is increased or loss of the ability of antioxidants is less. ${ }^{17}$ Volvariella volvacea culture in coconut water has the highest antioxidant activity, followed by rice bran and potato broth. In $S$. commune culture, the highest radical scavenging activity is in rice bran and coconut water, respectively. It also found that coconut water can affect the amount of fiber and antioxidant activity in the S. commune. ${ }^{18}$ Thus, the antioxidant ability of $S$. commune depends on the type of medium used for cultivation or use of the substances. ${ }^{19}$ In addition, coconut water contains three main sugars include glucose, fructose, and sucrose as a major energy source to produce fibers, can enhance the growth of S. commune and the amount of schizophyllan which is the main compound found in S. commune. This result is increased the antioxidant activity of $S$. commune. ${ }^{20}$ Coconut Board of India studied the 
comparative analysis of minerals in the tender and mature coconut water found that there are the same minerals such as potassium, sodium, calcium, magnesium and phosphorus but the amount analysis is different to affect the amount and properties of antioxidants in the $S$. commune extracts are different. Important factors affected on the growth and the number of antioxidants in S. commune such as controlled substances or growth hormones in coconut water are the natural hormone which is the liquid endosperm cells can be stimulated to grow and divide rapidly the morphology of the tissue. Many compounds in the juice will work together include amino acids, organic acids, nucleic acid, sugar, vitamins, growth regulators and nutrients necessary for the growth of $S$. commune fiber. ${ }^{21,22}$ As a result, this is alternative using coconut water replaced commercial hormone to increase antioxidant activity and total phenolic compounds in S. commune.

After S. commune brought through the boiling process to losing the TEAC and FRAP value compared to fresh mushrooms and total phenolic contents is lower than fresh mushrooms in all treatments. The effect of boiling on antioxidant activity and total phenolic contents of Pleurotus eryngii, Auricularia auricular, Pleurotus pulmonarius and Lentinula edodes found that $A$. auricular has lost antioxidant activity and phenolic compounds include the most and the boiling process changes the properties of antioxidants and total phenolic contents of $P$. eryngii, $P$. pulmonarius and L. edodes because the temperature and duration of heating affect the amount of antioxidants..$^{23,24}$ In this experiment, using heat from the boiling temperature of $90^{\circ} \mathrm{C}$ for $5 \mathrm{~min}$ which support carrot, cauliflower, Japan cucumber and bean through the curing stop antioxidant reaction to lose the antioxidant ability as high as $30-50 \%{ }^{25}$ However, factors that directly affect the stability of the phenolic compounds as well, including temperature, $\mathrm{pH}$, etc. lead to the number of phenolic compounds decreased due to decaying heat easily. ${ }^{26}$ The use of heat in the process, contributed to the number of phenolic compounds decreased. ${ }^{27}$ In general, natural phenolic compounds found in a variety of species which the most common is flavonoids and polyphenols such as lignin and tannin. The amount of total phenolic compounds in the diet from fruits and vegetables can vary according to the type and structure of the plant, how to plant, the ripening, processing and storage include the amount and composition of the hydroxyl groups and the replacement of aromatic ring. ${ }^{28}$ The results can be seen that heat is a major factor that affects the chemical composition of $S$. commune, such as antioxidants, the phenolic compounds, flavonoid and nutrients especially in the group of vitamins, botanical chemicals, secondary metabolites reduced these substances qualify as an antioxidant. Thus, the antioxidant activity in the $S$. commune reduced. In addition, the heat also makes enzymes in S. commune was destroyed or broken down naturally by the enzyme activity of antioxidants, the ability of antioxidants and nutrients, bioactive decline. The effect of heat at a temperature of $40-100^{\circ} \mathrm{C}$ for $30 \mathrm{~min}$ on the ability of antioxidants, the amount of total phenolic compounds and anthocyanin of fermented soy is found that when heated to a temperature higher antioxidant activity decreased. ${ }^{29}$ The duration of storage corn beverage with pasteurization at $4^{\circ} \mathrm{C}$ for 7 days had no effect on the amount of biologically active substances probably due to the low temperature storage. ${ }^{30}$ This value can be changed and slowed down as well as those found in the roasting process and herbal tea manufacturing process is heating the material affect the amount of the phenolic compounds and the antioxidant ability. ${ }^{27,31}$ So eating $S$. commune, should be cooked using the heat is not so high to continue features of antioxidants and phenolic compounds include the most outstanding.

Correlation analysis to determine the relationship between antioxidant activity and total phenolic compounds in the extracts found mostly a linear relationship because the determination of the total phenolic compounds is a measure of the ability of antioxidant activity. ${ }^{32}$ This study found that the antioxidant ability of the $S$. commune extract is quite in line with the amount of phenolic compounds, as well if the amount of phenolic compounds to show the ability of a substance, antioxidants are $\operatorname{good}^{33}$ but the relationship is not very high (Table 5). As phenolic compounds are the natural antioxidants such as a phenol which is capable of providing hydrogen lead to making antioxidants have to be replaced in the orthophosphate with a group that can make the electrons easier. The antioxidant ability which can give electrons or hydrogen to free radicals is associated with a number and position of hydroxyl group. ${ }^{3}$ The S. commune extract which contains also other substances can be reduced Folin-Ciocalteu reagent has the same blue and inhibit DPPH free radicals was less than the total phenolic compounds. Therefore, the analysis of total phenolic compounds and DPPH antioxidant activity were relatively low. From the correlation coefficient of $S$. commune extracts in the boiled mushroom was negative value showed that the antioxidant activity of the extracts did not correlate with the amount of total phenolic compounds indicates that the total phenolic compounds may not be the main antioxidant activity of antioxidants, and is destroyed by heat, the number of phenolic compounds decreased. It is reported that the number of phenolic compounds are vary depending on the type of plant, the cultivation area, how to extract and analyze the experiment including standards-based solution. ${ }^{34}$

\section{CONCLUSION}

Findings of this study revealed that $S$. commune Fr. extracts exhibit higher antioxidant activity and total phenolic contents using coconut water for cultivation. Tender coconut water was suitable for holding the property of antioxidant in S. commune. It also found that the relationship between antioxidant activity and total phenolic contents of mushrooms was low in both groups. It was concluded that the antioxidant properties and total phenolic compounds in S. commune affected by coconut water and boiling. Therefore, the $S$. commune extract can be used as an easily available source of natural antioxidants and as a promising food supplements due to phenolic compounds presence for cardiovascular disease and cancer prevention. ${ }^{35}$

\section{ACKNOWLEDGEMENT}

Authors would like to acknowledge the National Research Council of Thailand for the full funding of the research project and providing all the necessary support through Suan Sunandha Rajabhat University, Bangkok, Thailand.

\section{CONFLICT OF INTEREST}

The authors did not declare any conflict of interest.

\section{ABBREVIATIONS}

TEAC: Trolox equivalent antioxidant capacity; FRAP: Ferric reducing antioxidant power; GAE: Gallic acid equivalents; TPC: Total phenolic contents

\section{REFERENCES}

1. Ames BN, Shigenaga MK, Hagen TM. Oxidants, antioxidants, and the degenerative diseases of aging. In Proceedings of the National Academy of Sciences of the United States of America. 1993;90(17):7915-22.

2. Halliwell B, Gutteridge JMC. Oxygen toxicity, oxygen radicals, transition metals and disease. Biochemistry Journal. 1984;219(1):1-14

3. Fang $Y Z$, Yang $S$, Wa G. Free radicals, antioxidants and nutrition. Nutrition 2002;18(10):872-9.

4. Halliwell B. Antioxidants and human diseases: a general introduction. Nutr Rev. 1997;55(1):44-52.

5. Mau JL, Lin HC, Chen CC. Antioxidant properties of several medicinal mushrooms Journal of Agricultural and Food Chemistry. 2002;50(21):6072-7. 
6. Wasser P, Weis L. Medicinal properties of substances occurring in higher basidiomycetes mushrooms: Current perspectives. International Journal of Medicinal Mushrooms. 1999;1(1):31-62.

7. Barros L, Ferreira MJ, Queiros B, Ferreira ICFR, Baptista P.Total phenols, ascorbic acid, $\beta$-carotene and lycopene in Portuguese wild edible mushrooms and their antioxidant activities. Food Chem. 2007; 103(2):413-9.

8. Oyetayo VO. Free radical scavenging and antimicrobial properties of extracts of wild mushrooms. Braz J Microbiol. 2009;40(2):380-6.

9. Mattila P, Konko K, Eurola M. Contents of vitamins, mineral elements, and some phenolic compounds in cultivated mushrooms. J Agric Food Chem. 2001;49(5):2343-8.

10. Heleno SA, Barros L, Sousa MJ, Martins A, Ferreira ICFR. Tocopherols composition of Portuguese wild mushrooms with antioxidant capacity. Food Chem. 2010;119(4):1443-50.

11. Han $\mathrm{CH}$, Liu $\mathrm{QH}, \mathrm{Ng} T B$, Wang HX. A novel homodimeric lactose-binding lectin from the edible split gill medicinal mushroom Schizophyllum commune. Biochemical and Biophysical Research Communication. 2005;336(1):252-7.

12. Kuo M. Schizophyllum commune. 2003 [cited 2017 Dec 2]. Available from: http:// www.mushroomexpert.com/ schizophyllum_commune.html.

13. Patel S, Goyal A. Recent developments in mushrooms as anti-cancer therapeutics: a review. Biotech. 2012;2(1):12-5.

14. Seephonkai P, Samchai S, Thongsom A, Sunaart S, Kiemsanmuang B, Chakuton K. $\mathrm{DPPH}$ radical scavenging activity and total phenolics of Phellinus mushrooms extracts collected from Northeast of Thailand. Chinese Journal of Natural Medicines. 2011;9(6):441-5.

15. Benzie IFF, Strain JJ. The ferric reducing ability of plasma (FRAP) as a measure of antioxidant power: the FRAP assay. Anal Biochem. 1996;239(1):70-6.

16. Tibuhwa DD. A comparative study of antioxidant activities between fresh and dry mushrooms in the genera Cantharellus and Afrocantharellus from Tanzania. Food Nutr Sci. 2014;5:212-21.

17. Mantena SK, Badduri JSR, Siripurapu KB, Unnikrishnan MK. In vitro evaluation of antioxidant properties of Cocos nucifera Linn. water. Nahrung. 2003;47(2):126-31.

18. Rich-Milton RD, Ma-Ellenita GDC. Antibacterial and antioxidant activities of three citrus leaves extracts. Der Pharmacia Lettre. 2016; 8(13):167-70.

19. Elisashvili V. Submerged cultivation of medicinal mushrooms: bioprocesses and products (review). Int J Med Mushrooms.2012;14(3):211-39.

20. Rau U. Production of Schizophyllan. In: Methods in Biotechnology, Carbohydrate Biotechnology Protocols, C. Bucke ed. Humana Press, Inc. Totowa, New Jersey, USA. 1999:43-55.

21. Young JWH, Ge L, Ng YF, Tan SN. The Chemical composition and biological properties of coconut (Cocos nucifera L.) water. Molecules. 2009;14(12):514464.

22. DebMandal M, Mandal S. Coconut (Cocos nucifera L.: Arecaceae): In health promotion and disease prevention. Asian Pac J Trop Med. 2011;4(3):241-7.

23. Chuayjarern P. The effect of boiling on antioxidant activity of King Oyster Mushroom, Jew's ear mushroom, Phoenix oyster mushroom and Shitake mushroom. In $9^{\text {th }}$ National and International Conference. 2015.

24. Loannou I, Hafsa I, Hamdi S, Charbonnel C, Ghoul M. Review of the effects of food processing and formulation on flavonol and anthocyanin behavior. J. Food Eng. 2012;111(2):208-17.

25. Jimenez-Monreal AM, Garcia-Diz L, Martinez-Tome M, Mariscal M, Murcia MA J Food Sci. 2009;74(3):97-103

26. Lapnitiporn S, Laohakunjit N, Kerdchoechuen O. Physico-chemical composition and antioxidant activity of cashew apple juice. Agricultural Sci J. 2012;43(2) (Suppl.):409-12.

27. Lorsuwan $P$, Rachtanapun C, Chantanawarangoon S. Total phenolics, radical scavenging capacity and antimicrobial property of fruit peels. In Proceedings of 46 ${ }^{\text {th }}$ Kasetsart University Annual Conference: Agro-Industry. 2008;554-61.

28. Buasod P. Antioxidant capacity test of tea beverage by cyclic voltammetry. Thesis for master's degree of Science, Graduate School, Silpakorn University. 2006.

29. Lin YC. Chou CC. Effect of heat treatment on total phenolic and anthocyanin contents as well as antioxidant activity of the extract from Aspergillus awamori fermented black soybeans, a healthy food ingredient. International journal of food science and nutrition. 2009;60(7):627-36.

30. Phosanam A, Sarapat S, Jaitus S. Antioxidants, phenolic and flavonoid from corn silk beverage. In Proceeding of $1^{\text {st }}$ KMITL Agro-Industry Conference. 2012

31. Areekul V, Mettamethar N. The impact of manufacturing process on polyphenol content and antioxidant capacity of herbal tea infusion. In the $8^{\text {th }}$ Agro-Industrial Conference. 2005;15-6.

32. Huang $D, O u B$, Prior RL. The chemistry behind antioxidant capacity assays Journal of Agricultural and Food Chemistry. 2005;53(6):1841-56.

33. Maisutthisakun P. Evaluation of antioxidant potential and phenolic Constituer in selected Thai indigenous plant extracts. Thesis for master's degree of Science, Khon Kaen University. 2006.

34. Huda FN, Noriham A, Norrakiah AS, Babji AS. Antioxidant activity of plants methanolic extracts containing phenolic compounds. African Journal of Biotechnology .2009;8(3):484-9.

35. Sudjaroen Y. Plant-derived phenolic antioxidants and cancer prevention. Thai Cancer J. 2009;29(9):126-34.

\section{GRAPHICAL ABSTRACT}

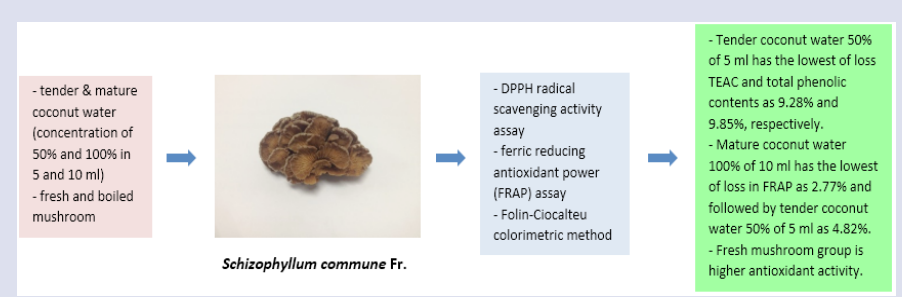

\section{SUMMARY}

- The S. commune extract with tender coconut water has a high antioxidant activity and percentage loss of TEAC and FRAP likely lower compared to other treatments.

- The boiling process changes the properties of antioxidants and total phenolic contents of S. commune. The TEAC, FRAP value and total phenolic contents of boiled mushrooms are lower than fresh mushrooms in all treatments.

- The correlation between antioxidant activity and total phenolic contents of mushrooms is low in both groups.

\section{ABOUT AUTHORS}

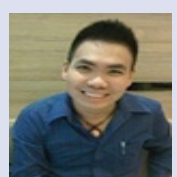

Chanate Wanna Obtained his M.Sc. in Biochemistry, Faculty of Medicine, Siriraj Hospital, Mahidol University, Thailand. Currently, he is the lecturer at Division of Biology, Faculty of Science and Technology, Suan Sunandha Rajabhat University, Thailand. He has experiences in the area of Biology and Biochemistry working mainly in nutrition, antioxidant, molecular biology, zoology and biodiversity.

Cite this article: Wanna $\mathrm{C}$ and Sudhadham M. The Effect of Coconut Water and Boiling on Antioxidant Activity and Total Phenolic Contents in Schizophyllum commune Fr. Pharmacog J. 2018;10(5):925-31. 